\title{
DAKWAH DALAM PERSPEKTIF AL-QUR'AN DAN HADITS
}

\author{
Novri Hardian ${ }^{1}$ \\ 1UIN Imam Bonjol Padang \\ Email : novri.hardian@yahoo.co.id
}

\begin{abstract}
Dakwah merupakan usaha untuk mengajak manusia ke jalan Allah. Dalam kajian ilmu filsafat dakwah dikenal istilah ontology ilmu dakwah. ontology ialah ilmu tentang yang ada. Sedangkan ontologi dakwah membahas hal yang ada atau sumber dari segala sesuatu maka dalam penerapan dakwah, yang menjadi sumber dakwah adalah al-Qur'an dan hadist maka perlu diperhatikan apa yang menjadi sumbernya. Sehingga dapat menambah khazanah ilmu pengetahuan bagi para juru dakwah.
\end{abstract}

Keyword : dakwah, al-Qur'an, hadist

\section{PENDAHULUAN}

A. Pengertian Dakwah Dalam Perspektif Al-Qur'an Dan Hadits

a. Pengertian Dakwah Secara Bahasa.

Dakwah dalam bahasa Arab berasal dari kata (da'a yad'u, da'watan), berarti menyeru, memanggil, mengajak, menjamu (Mahmud yunus, 1989 : 127). Atau kata $d a^{\prime} a, y a d ' u, d u a a n, d a ' w a h u$, berarti menyeru akan dia (Luis Ma'luf, 1997: 216)

Asal kata dakwah dalam berbagai bentuknya (fi;il dan isim), terulang dalam Al-Qur'an sebanyak 211 kali (Muhammad Fu'ad abdu albaqi, 1992: 326), dengan rincian, dalam masdar terulang 10 kali, fi'il Madhi 30 kali, Fi'il Mudhari' 112 Isim Fa'il 7 kali dan sedangkan dengan kata dua sebanyak 20 kali,

Dakwah dan yang seakar dengan kata Da'wah dalam bentuk
Masdar 10 kali dan dalam AIQur'an, yaitu dalam surat alBaqarah: 186,

Al-a'raf: 5, Yunus: 10, 89, al-Rad : 14, Ibrahim : 44, AI-Anbiya': 15, ar-Rum 25, al-Ghafir: 43

Dalam bentuk fi'il Madhi diulang 30 kali , antara lain dalam surat 186, ali- Imran: 38, al-Anfal: 24, Yunus: 12, al-Rum: 25, alzumar 8,49, Fushilat: 33, adDukhan: 22, al-Qamar: 10 dan lain-lain.

Sedangkan kata da'wah dalam bentuk fi'il mudhari' diulang sebanyak 112 kali, antara lain dalam surat al-baqarah :271, ali-imran :104, annisa'117 (dua kali ), al-an'am :52, 108, yunus 66, Hud :101, al-rad :14, an-nahl : 20, al-isra':67, Al-kahfi : 28, al-Hajj: 62, al-furqan :68, al-Qasash :41, alankabut :42 dan lain sebagainya.

Dalam bentuk fi'il amar diulang sebanyak 32 kali, antara lain : surat al-baqarah :61, 68, 70, al- 
a'raf :134, dan an-nahl:125, al-hajj :67, al-qashash: 87 asy-syura : 15, ad-zukhruf :49 dan lain-lain.

Dalam bentuk Isim Fa'il diulang 7 kali, yaitu dalam surat alBaqarah: 186, Thaha :108, al-Ahzab : 46, al-Ahqaf. 31,32 dan al-Qamar: 6,7

Berdasarkan uaraian di atas ternyata kata dakwah dalam al-Quran dari berbagai bentuknya terdapat 211 kali, ini menggambarkan bahwa dakwah itu sangat penting dan harus di lakukan oleh umat Islam, baik secara individu ataupun secara kelompok, dengan terencana dan propesional sesuai dengan tujuan dakwah itu sendiri.

Berdasarkan penelusuran terhadap ayat-ayat di atas ternyata tidak semua kata $D a ' w a h$ yang berarti ajakan dan seruan, bahkan ada yang berarti do'a dan permohonan. Namun menurut hemat penulis dakwah juga dapat di artikan menerangkan atau menjelaskan, hal ini dapat kita lihat dalan surat alBaqarah ayat 256
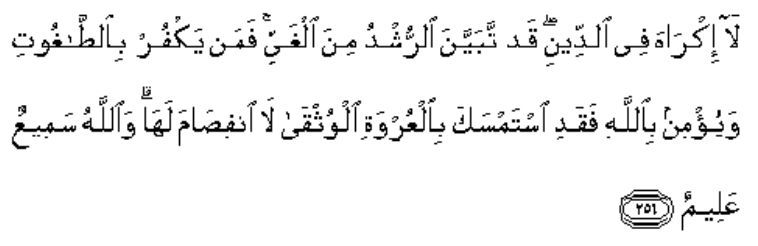

Tidak ada paksaan untuk (memasuki) agama (Islam); sesungguhnya telah jelas jalan yang benar daripada jalan yang sesat. Karena itu barangsiapa yang ingkar kepada Thaghut dan beriman kepada Allah, maka sesungguhnya ia telah berpegang kepada buhul tali yang amat kuat yang tidak akan putus. Dan Allah Maha Mendengar lagi Maha Mengetahui.

Jadi ayat ini menerangkan bahwa dakwah itu cukup dengan menjelaskan atau menerangkan dan tidak boleh dengan paksa. Dakwagh berarti permohonan, ini dijelaskan Allah dalam al-qur'an surat al-baqarah 186 :

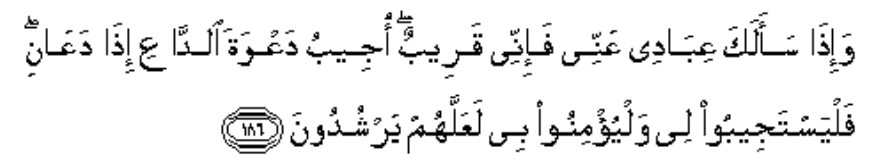

Dan apabila hamba-hamba-Ku bertanya kepadamu tentang $A k u$, maka (jawablah), bahwasanya Aku adalah dekat. Aku mengabulkan permohonan orang yang berdoa apabila ia memohon kepada-Ku, maka hendaklah mereka itu memenuhi (segala perintah-Ku) dan hendaklah mereka beriman kepada-Ku, agar mereka selalu berada dalam kebenaran.

Sedangkan dakwah yang berarti menyeru /seruan ditugaskan Allah dalam surat Ibrahim ayat 44 yang berbunyi:

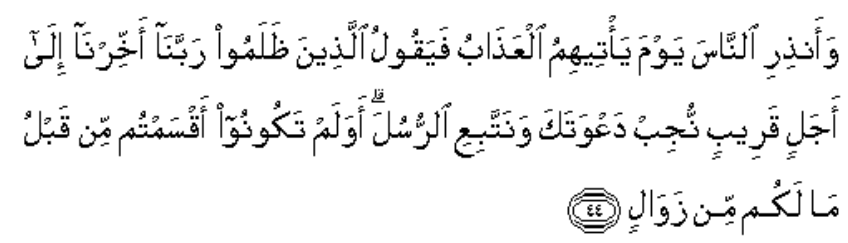

Dan berikanlah peringatan kepada manusia terhadap hari (yang pada waktu itu) datang azab kepada mereka, maka berkatalah orangorang yang zalim: "Ya Tuhan kami, beri tangguhlah kami (kembalikanlah kami ke dunia) walaupun dalam waktu yang sedikit, niscaya kami akan mematuhi seruan Engkau dan akan mengikuti rasul-rasul." (Kepada mereka dikatakan): "Bukankah kamu telah bersumpah dahulu (di dunia) bahwa sekali-kali kamu tidak akan binasa?

Dakwah dalam artian ajakan terlihat dalam surat ali-imran 104 

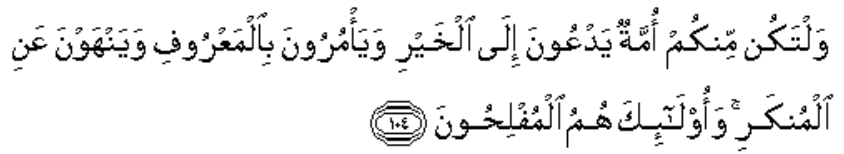

Dan hendaklah ada di antara kamu segolongan umat yang menyeru kepada kebajikan, menyuruh kepada yang ma'ruf dan mencegah dari yang munkar merekalah orang-orang yang beruntung.

Dari pengertian dakwah yang terdapat dalam ayat-ayat di atas dapat penulis ambil suatu kesimpulan bahwa dakwah yang berarti menyeru, memohon ataupun mengajak dalam ayat tersebut bermaksud membawa manusia kepada jalan dan situasi yang baik atau dengan kata lain, dakwah dalam arti permohonan atau doa kepada Tuhan dan Allah menjanjikan akan mengabulkannya, dengan syarat melakukan semua perintah Allah dan beriman padanya. Kemudian dakwah yang berarti mengajak kepada ma'ruf yang diredhai allah SWT dan melarang berbuat mungkar, perbuatan yang dibenci oleh Allah.

\section{B. Dakwah Ditinjau dari Segi Istilah}

Secara istilah pengertian Dakwah sangat beragam, hal ini bergantung pada sudut pandang dan pemahaman para pakar dalam memberi pengertian dakwah itu, sehingga yang diberikan para pakar yang satu dengan yang lain sering terdapat persamaan. Untuk lebih jelasnya beberapa defenisi dakwah menurut para ahli.

1. Syekh Ali MahFudz.

Di dalam kitabnya Hidayahtul Mursyidin, mengintrodusir pengertian dakwah sebagaimana dikutib oleh Salmadanis dalam bukunya filsafat Dakwah dan A. Rasyad Shaleh dalam bukunya Manajemen Dakwah Islam, yaitu :

Artinva: "Mendorong manusia agar berbuat kebajikan dan petunjuk, menyuruh berbuat yang ma'ruf dan melarang yang mungkar agar mereka dapat kebahagiaan di Dunia dan di akhirat

Jadi yang dimaksud oleh Syeh Ali Mahjudz ini adalah sangat umum, yaitu mendorong manusia agar berbuat kebajikan menyuruh kepada yang ma'ruf dan mencegah dari yang mungkar.

1. Abu Bakar Aceh

Menurut Abu Bakar Aceh yang dikutip oleh Totok Jurnantorc dalam bukunya Psikologi Dakwah, menulis defenisi dakwah, adalab perintah mengadakan seruan kepada manusia untuk kembali dan hidup sepanjang ajaran Allah yang benar, dilakukan dengan penuh kebijaksanaan dan nasehat yang baik.

Jadi Abu bakar Aceh mendepenisikan dakwah, di awali dengan kata-kata perintah mengadakan seruan kepada manusia.

2. Khadir Khatib Bandaro.

Dalam bukunya yang berjudul Suatu Studi tentang ilmu Dakwah, Tabligh, Menuju Para Da'i Profesional mensinyalir pengertian dakwah sebagai aktivitas yang dilakukan dengan sadar dan senagaja dalam upaya meningkatkan taraf hidup manusia yang sesuai dengan ketentuan Allah dan Rasul oleh seseorang sekelompok orang secara sadar dan dalam upaya menimbulkan pengertian, 
kesadaran dan pengalaman terhadap ajaran agama Islam

Jadi khaidir katib bandaro mendepenisikan dakwah, di awali -an kata-kata aktivitas yang di lakukan dengan sadar dan di segaja.

\section{M. Arifin.}

Memberikan batasan dakwah dalam pengertian suatu ajakan dalam bentuk, tulisan, tingkah laku dan sebagainya

yang dilakukan secara sadar dan berencana dalam usaha mempengaruhi orang lain baik secara Individual maupun secara kelompok supaya timbul dalam dirinya satu pengertian, kesadaran, sikap, penghayatan, serta penghayatan terhadap ajakan agama sebagai masage yang disampaikan kepadanya dengan tanpa adanya unsur-unsur pelaksanaan (Arifin, 1994: 6).

Jadi Pada hakikatnya Arifin berusaha memberikan batasan dakwah dalam pengertian yang sangat luas, dimana segala sesuatu upaya menyebar luaskan dalam segala lapangan hidup manusia, tentu arikel-artikel kegarnaan di media elektronik termasuk aktivitas dakwah. Defenisi-defenisi tersebut
di atas, meskipun terdapat
perbedaan perumusan, tetapi apabila dibandingkan satu sama lain dapat

dirumuskan bahwa dakwah adalah segala upaya untuk menyebar luaskan Islam kepada orang lain dalam segala lapangan kehidupan manusia untuk

kebahagian hidup di dunia dan di akhirat, dengan kata lain segala aktivitas yang dilakukan secara sadar dan sengaja oleh manusia beragama Islam dengan baik dan tanggung jawab disertai akhlak yang mulia agar mereka memperoleh sa'adah masa kini dan masa mendatang.

Jadi menurut hemat penulis yang yang dimaksud dengan defenisi-defenisi di atas adalah mengembalikan manusia kepada fitrahnya, yang di maksud dengan fitrah di sini bukan sekedar pengabdian yang berupa ibadah, tetapi adalah sangat mendetail, seperti mata, telinga, tenaga, akal, hati, di manfaatkan masing-masing yang di motori denan al-qur'an dan hadits.

b. Subjek dakwah

Subjek adalah pelaku, atau orang yang melakukan. Dalam bahasa Arab, subjek dakwali dikenal dengan istilah da'i (orang yang berdakwah), seimbangan dengan Isim fa'il (orang yang melakukan pekerjaan).

Di dalam Al-Qur'an yang membicarakan masalah dakwah yang tersebar dalam beberapa surat seperti yang telah diuraikan di atas, diperoleh gambaran berkenaan dengan subjek/pelaku dakwah, di antaranya:

1. dalam surat Al-baqarah ayat 186:

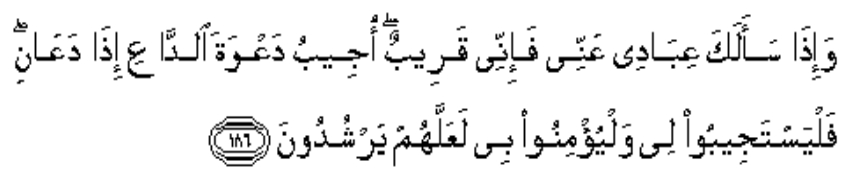

Dan apabila hamba-hamba-Ku bertanya kepadamu tentang $A k u$, maka (jawablah), bahwasanya Aku adalah dekat. Aku mengabulkan permohonan orang yang berdoa apabila ia memohon kepada-Ku, maka hendaklah mereka itu memenuhi (segala perintah-Ku) dan hendaklah 
mereka beriman kepada-Ku, agar mereka selalu berada dalam kebenaran.

Diartikan dalam "permohonan" atau "do'a", maka Subjek Dakwah dalam ayat ini adalah seorang hamba (siapa saja) yang berdo'a kepada Allah. Dan ini digolongkan kepada subjek dakwah Fardiyah (individu).

2. Surat yunus ayat 25

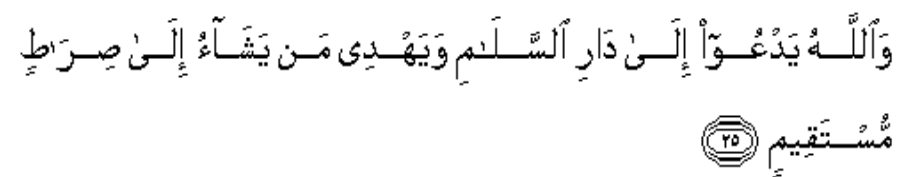

Allah menyeru (manusia) ke Darussalam (surga), dan menunjuki orang yang dikehendaki-Nya kepada jalan yang lurus (Islam)

Dalam ayat ini kata Dakwah Fi'il Mudhari', yang diartikan dengan "menyeru" maka yang menjadi subjek Dakwah dalam ayat ini adalah Allah yang mengajak manusia kepada Sorga (kesenagan akhirat).

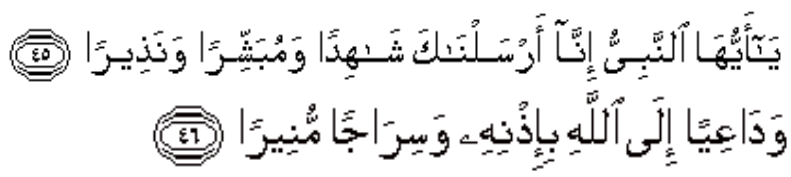

Artinya Hai Nabi, sesungguhnya Kami mengutusmu untuk jadi saksi, dan pembawa kabar gemgira dan pemberi peringatan, dan untuk jadi penyeru kepada Agama Allah dengan izin-Nya dan untuk jadi cahaya yang menerangi.

Kata (isim fi'il) yang menjadi subjek ( $d a^{\prime} i$ ) adalah Nabi Muhammad sebagai pelaksana dakwah, menjadi mubasyir terhadap umatnya.

Selain ayat-ayat dikemungkakan di atas, masih banyak ayat Al-Qur'an yang membahas subjek Dakwah, oleh karenanya, yang menjadi subjek Dakwah tidak hanya orang tertentu saja, misalnya: Ustad, Buya, Ulama atau bahkan cendekiawan muslim saja melainkan seluruh, atau setiap muslim, apakah dia lelaki atau perempuan, apabila mereka sudah baigh clan berakal.

Dengan demikian, dapat dipahami bahwa selain para Rasul sebagai subjek (pelaksanaan dakwah yang dipilih langsung oleh Allah, juga subjek (perintah $=$ pelaksana $)$ dakwah ditunjukkan kepada seluruh umat beriman. Untuk itu dapat ditegaskan bahwa subjek dakwah adalah mencakup setiap muslim dari seluruh lapisan masyarakat tanpa kecuali, laki-laki dan perempuan dengan tingkat kemampuanya masing-masing, kapan dan dimanapun mereka berada

c. Objek kajian dakwah.

Kata Objek dapat diartikan sebagai "sasaran yang akan dituju", orang yang menjadi sasaran pertimbangan', "atau tempat yang ditinjau"

dalam kajian ilmu dakwah, objek dakwah, disebut juga dengan istilah 'mad'u. Kata mad'u merupakan isim maf'ul dan dari kata da'wahu, yad'uhu kemudian mad'u. Menurut Istilah berarti 'siapa saja yang kepadanya dihadapkan dakwahatu yang menjadi sasaran dakwah.

Manusia sebagai sasaran dakwah atau manusia sebagai penerima dakwah baik individu maupu kelompok, baik beragama Islam maupun non Islam, apakah kafir, musyrik, munafik, mulhid,fasiq dan sebagainya.

Firman allah dalam surat saba' ayat 28 :

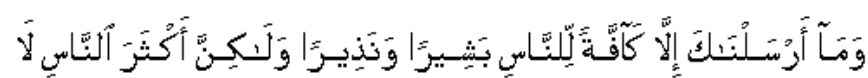

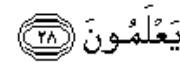

Dan Kami tidak mengutus kamu, melainkan kepada umat manusia seluruhnya sebagai pembawa 
berita gembira dan sebagai pemberi peringatan, tetapi kebanyakan manusia tiada mengetahui.

Ayat di atas menjelaskan bahwa manusia yang belum beragama Islam dakwah disini bertujuan untuk mengajak mereka agar megikuti agama Islam sedangkan berdakwah kepada yang sudah beragama Islam dakwah yang bertujuan untuk meningkatkan kualitas Iman, Islam. dan Ihsan.

Sasaran atau dakwah atau mad'u dapat dikategorikan berdasarkan beberapa faktor, dari segi Iman, Mad'u dibagi menjadi dua, yang sudah beriman sebut umat jabah dan yang belum beriman disebut umat dakwah. Yang pertama dengan meningkatkan keimanan dan kelslaman, dan yang kedua dengan target mengajak masuk Islam. Dari segi status sosial ekonomi. mad'u menjadi kelompok elite (mala') dan kelompok lemah dan bertindak (dhu'afa dan musdh'afin). Dalam sejarah Nabi, lebih sulit meerima dakwah. Penolakan kelompok elit terhadap dakwah termasuk dalam surat hud 2527:

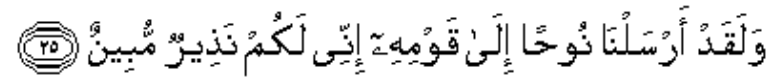

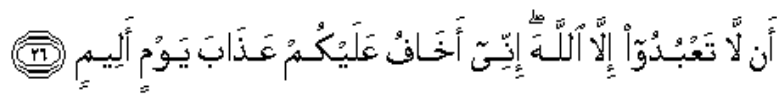

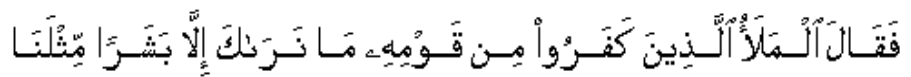

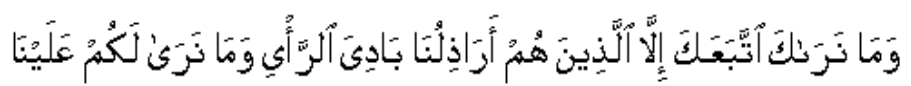

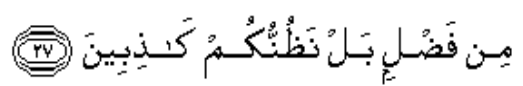

Dan sesungguhnya Kami telah mengutus Nuh kepada kaumnya, (dia berkata): "Sesungguhnya aku adalah pemberi peringatan yang nyata bagi kamu, agar kamu tidak menyembah selain Allah. Sesungguhnya aku takut kamu akan ditimpa azab (pada) hari yang sangat menyedihkan." Maka berkatalah pemimpin-pemimpin yang kafir dari kaumnya: "Kami tidak melihat kamu, melainkan (sebagai) seorang manusia (biasa) seperti kami, dan kami tidak melihat orang-orang yang mengikuti kamu, melainkan orang-orang yang hina dina di antara kami yang lekas percaya saja, dan kami tidak melihat kamu memiliki sesuatu kelebihan apapun atas kami, bahkan kami yakin bahwa kamu adalah orang-orang yang dusta."

Kaum kaum elit menolak dakwah karena takut kehilangan laki-laki "istimewa" yang didapat dengan cara-cara zalim (seperti fir'aun, Qarun, haman, ruhban, dalam kasus musa AS, Umayyah ibnu khalab dan abu lahab dalam kuasa nabi muhammad SAW, sedangkan kaum du'afa merasa senang menerima dakwah karena hak-hak mereka diperjuangkan.

Objek kajian selain manusia juga mencakup golongan jin ayat 1 , surat alahqaf ayat 23-29, yang menceritakan alqur'an yang dibaca, sampai mereka beriman dan mengajak teman-temannya juga beriman.

Manusia sebagai objek dakwah yang mana asal kejadiannya berasal dari tahap sebaimana yang terdapat dalam surat fatir ayat 11

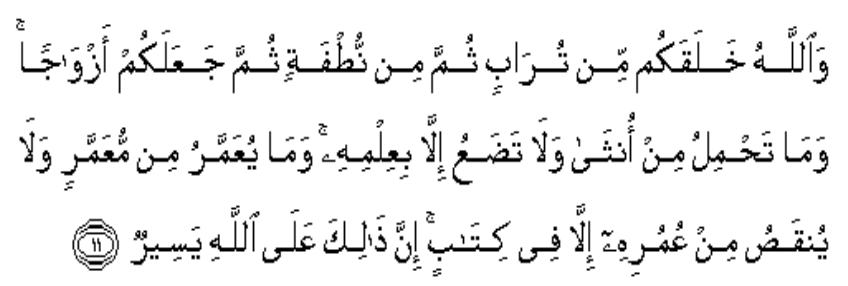

Dan Allah menciptakan kamu dari tanah kemudian dari air mani, kemudian Dia menjadikan kamu berpasangan (laki-laki dan perempuan). Dan tidak ada seorang perempuanpun mengandung dan tidak (pula) 
melahirkan melainkan dengan sepengetahuan-Nya. Dan sekalikali tidak dipanjangkan umur seorang yang berumur panjang dan tidak pula dikurangi umurnya, melainkan (sudah ditetapkan) dalam Kitab (Lauh Mahfuzh). Sesungguhnya yang demikian itu bagi Allah adalah mudah.

Ayat ini menjelaskan asal mula kejadian manusia, yang mana ada dua tafsiran yakni, pertama bahwa asal manusia pertama, yaitu nenek moyang manusia, tegas nabi adam langsung diciptakan dari tanah kemudian anak dari nabi adam as sendiri dan manusia keturunan adam seluruhnya terjadi dari nutfah, yaitu sperma yang berasal dari ayah dan dan sel telur ibu yang telah bergabung dalam rahim jadi satu, kedua, boleh juga ditafsirkan bahwa masing-masing kita manusia memang dari tanah.makanan yang kita semuanya berasa dari tanah. Sayuran, buah-buahan dan sapi, sapi makan rumput yang berasal dari tanah.

d. Materi dakwah

Materi dakwah merupakan unsur penting dalam pelaksanaan dakwah, karena tanpa materi yang akan disampaikan si da'i kepada mad'unya. Dalam hal ini yang menjadi materi dakwah merupakan ajaran Islam sendiri (Abdul Karim Zaidan, 2000:94). Jadi semua ajaran Islam bisa dijadikan materi dakwah. Yang menjadi materi dakwah pada garis besarnya dapat dikelompokkan sebagai berikut:

1. Aqidah meliputi : Iman kepada Allah, malaikat, kitab-kitabNya rasulnya dan hari akhir serta qadar baik dan qadar buruk.

2. Syari'ah meliputi : ibadah muamalah.

3. Akhlak meliputi : akhlak kepada sang pencipta, akhlak kepada semua makhluk ciptaan-Nya.

Abdul munir Mulkan, menambahkan bahwa yang menjadi materi atau isi dakwah (Abdul Munir Mulkan, 1996: 57) adalah sebagai berikut:

1. tantangan kristen terhadap Islam.

2. Kegiatan diam-diam dari budhisme di indonesia.

3. Kelemahan-kelemahan Islam dalam kehidupan politik, ekonomi, sosial dan hukum

4. Keadaan sebagian umat Islam yang hampir-hampir menyerupai masa abstrak yang kehilangan tegangan batin.

5. Ketiadaan taqwa dan sabar dikalangan sebagain umat Islam.

6. Lemahnya sikap amar ma'ruf nahi mungkar.

7. Oportunitisme dan absucurantisme dikalangan sebagian umat Islam.

8. Kemiskinan dan kemelaratan rakyat.

9. Akhlaqul qarimah sebagai bentuk non ferbal dari dakwah

10. Padangan dan tujuan hidup Islam.

Kesepuluh persoalan di atas adalah masalah penting yang perlu dibahas dakwah pada masa sekarang dan masa yang akan datang. Namun tidak terlepas dari persoalan tauhid, aqidah dan syari'ah sebagai materi dasar dakwah.

Ada beberapa materi dakwah 
yang disyari'atkan al-qur'an yaitu:

1. Al-qur'an surat Ali-Imran ayat 104

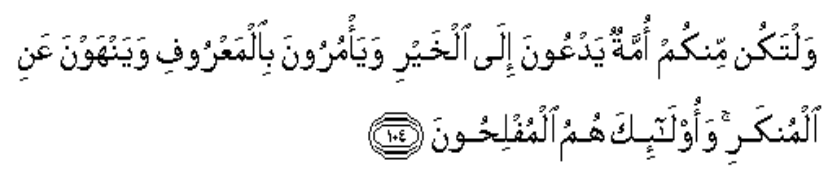

Dan hendaklah ada di antara kamu segolongan umat yang menyeru kepada kebajikan, menyuruh kepada yang ma'ruf dan mencegah dari yang munkar; merekalah orangorang yang beruntung.

\section{Al-Qur'an surat} Muhammad ayat 38.

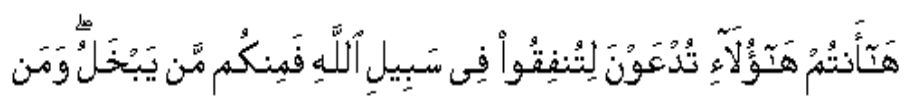

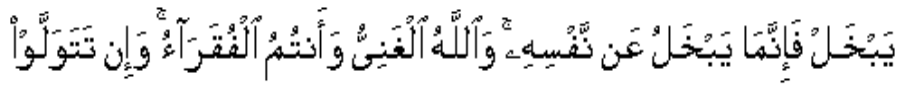

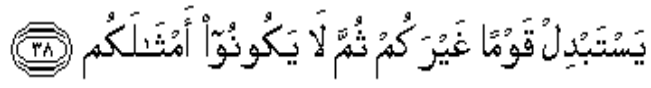

Ingatlah, kamu ini orang-orang yang diajak untuk menafkahkan (hartamu) pada jalan Allah. Maka di antara kamu ada yang kikir, dan siapa yang kikir sesungguhnya dia hanyalah kikir terhadap dirinya sendiri. Dan Allah-lah yang Maha Kaya sedangkan kamulah orangorang yang berkehendak (kepadaNya); dan jika kamu berpaling niscaya Dia akan mengganti (kamu) dengan kaum yang lain; dan mereka tidak akan seperti kamu ini.

\section{Surat al-Fath ayat 16}

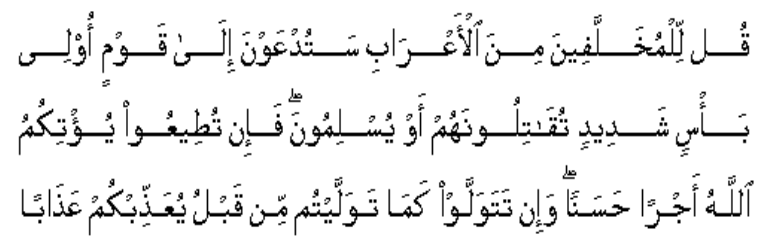

Katakanlah kepada orangorang Badwi yang tertinggal: "Kamu akan diajak untuk (memerangi) kaum yang mempunyai kekuatan yang besar, kamu akan memerangi mereka atau mereka menyerah (masuk Islam). Maka jika kamu patuhi (ajakan itu) niscaya Allah akan memberikan kepadamu pahala yang baik dan jika kamu berpaling sebagaimana kamu telah berpaling sebelumnya, niscaya Dia akan mengazab kamu dengan azab yang pedih."

4. Surat Ali-Imran ayat 23:

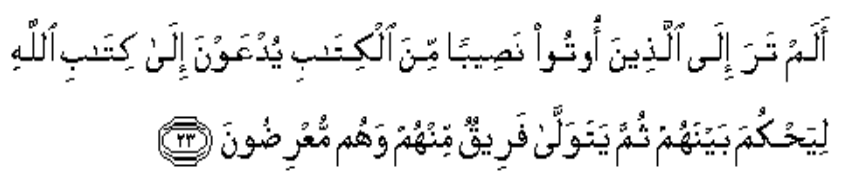

Tidakkah kamu memperhatikan orang-orang yang telah diberi bahagian yaitu Al Kitab (Taurat), mereka diseru kepada kitab Allah supaya kitab itu menetapkan hukum diantara mereka; kemudian sebahagian dari mereka berpaling, dan mereka selalu membelakangi (kebenaran).

Pada ayat ini dakwah di sini dengan ajaran para nabi, da'i dari beberapa uraian di atas di pahami bahwa materi dakwah adalah ajaran Islam yang terdapat dalam al-qur'an aqidah, syari'ah dan muamalah dan sunah rasulullah serta nilai-nilai baik yang terdapat dalam masyarakat (adat).

e. Metode dakwah

Dakwah adalah panggilan umat manusia di seluruh dunia ke jalan 
Allah dengan penuh kebijaksanaan dan petunjukpetunjuk yang baik dan berdiskusi dengan cara sebaikbaiknya, dengan kata lain dakwah sebagai uatu usaha- usaha menyerukan dan menyampaikan kepada perorangan manusia dan seluruh umat manusia, konsepsi islam tentang pandangan dan tujuan manusia hidup di dunia ini, yang meliputi amal ma'ruf anhi munkar dengan berbagai macam dan media yang diperbolehkan akhlak dan membimbing pengalamannya dalam peri kehidupan masyarakat dan peri kehidupan bernegara (Abdul Munir Mulkan, 2002:113).

Metode adalah suatu cara dan prosedur

Sedangkan al-Qur'an semenjak pertama kali diturunkan, sekarang dan di masa yang mendatang, selalu menjadi sumber rujukan dan isnpirasi dakwah, pernyataan itu diperkuat beberapa bukti dan argumentasi, baik secara normatif atau secara empirik, sebagai berikut:

a. Keberadaan al-qur'an sebagai wahyu atau firman Allah (kallamullah) mempunyai identitas mutlak dan universal sehingga nilai-nilai kelakuannya tidak terbatas dimensi waktu (dulu, sekarang, dan yang akan datang ) dan dimensi ruang dan tempat (di sana di sini dan di situ) hal ini di kenal dengan proposisi yang menyebutkan.

b. Kandungannya banyak memuat pesan moral tentang dakwah, yakni upaya seruan, ajakan, bimbingan, dan arahan menuju ashshirath al mustaqim (din al islam. c. Al-qur'an secara khusus banyak memuat pesan moral tentang dakwah, yakni upaya seruan, ajakan, bimbingan, dan arahan menuju ash shirath al mustaqim (din al-islam)

d. Al-qur'an secara khusus banyak memuat dan memperkenalkan istilah-istilah dakwah seperti :

e. Secara eksplisit, term dakwah dalam al-qur'an ada yang diungkapkan dalam perintah (amr)

f. Telah terbukti dalam sejarah, alquran mampu memotivasi dan ispirasi perubahan sebuah peradaban manusia dari kondisi jahiliyah (zulumat) menuju kehidupan keterang benderangan (an-nur). Yuhriju hum min ash zhulumat ila nur.

g. Al-qur'an melahirkan sebuah ajaran, pranata sosial, kebudayaan, dan peradaban baru.

Sebagai kitab dakwah yang peuh hikmah, al-qur'an banyak mengintrodusir term-term dakwah. Setiap terma mengandung sarat makna terbuka dan menantang utuk ditelaah, dipahami, ditafsirkan dan dihubungkan dengan teori dan realitas kekiniaan. Hal ini sesuai dengan dengan semangat kehadirat al-qur'an sebagai petunjuk (hudan), penjelasan (albayyinat), dan pemilahan (furqan). Yakni sebagai petunjuk, keterangan, dan penjelasan serta pemilahan terhadap segala persoalan dan kejadian yang muncul. Dengan demikian, idealnya al-qur'an betul-betul hadir di tengah-tengah kehidupan sosial budaya yang menerangi, interaktif, dan komunikatif dengan zamannya (Asep Muhidin, 2002:29).

Esensi dari kandungan makna dakwah adalah adanya unsur upaya yang 
serius dan dinamis. Al-qur'an sebagai rujukan dakwah (masdar ad-da'wah), di samping hampir semua terma dakwah yang di intriodusirnya di ekspresikan dengan kata kerja (fi'il madhi, mudhari dan amr) juga memerintahkan kegiatan dakwah secara tegas.

Hal itu memberi isyarat bahwa upaya kegiatan dakwah, di samping harus dilaksanakan secara serius, juga dituntut sistematis dan akademis. Karena aktivitas dakwah, dilihat dari segi pelakunya adalah manusia mukallaf yang memiliki totalitas jalinan syaraf yang sinergik, aktifitas yang pelakunya itu secara runtut akan muncul dari sebuah kesadaran. Adapun kesadaran muncul dari sebuah pemahaman.

Al-Qur'an mempunyai tugas lain dalam kehidupan islami, disamping funsinya sebagai metode aktifitas bagi kehidupan muslim, undang-undang hukum dan tasyri' bagi masyarakat muslim atau bagi negara muslim, sebagai undang-undang dakwah islamiayah.

Al-Qur'an sebagai sumber utama ajaran Islam tersusun sedemikian rupa menjadi petunjuk dalam menjalani waktu kehidupannya. Kandungan alqur'an tidak terbatas pada ajaran nilai, hukum sejarah dan sebagai ilmu pengetahuan saja, tapi juag mengandung usnur metodologi berbagai ilmu pengetahuan, bahkan susunan kata, kata yang dipilih dalam bahasa arab, susunan kalimat, hubungan masalah yang di bicarakan, semua sarat dengan informasi, ilmu dan metodologi.

Dakwah dalam al-quran berarti ajakan kepada kebaikan, yaitu ajakan kepada agama Islam, membangun masyarakat madani yang qur'ani, selalu dalam amar ma'ruf nahi mungkar. Dakwah merupakan seperangkat aktifitas yang dilakukan oleh setiap muslim sesuai dengan kemampuannya, bertujuan menjadikan seluruh umat manusia meyakini dan mengamalkan ajaran Islam dengan baik dan bertanggung jawab serta diiringi dengan akhlak mulia demi memperoleh kebahagiaan sekarang dan yang akan datang.

\section{KESIMPULAN}

Dakwah dalam perspektif al-Qur'an dan hadist sudah dapat menjelaskan unsurunsur dakwah baik dari segi da'i, mad'u, media, Metode dan tujuan dakwah sehingga dapat digunakan dalam tantanan praktis dalam pelaksanaan dakwah.

Dalam pelaksanaan dakwah harus merujuk pada sumber yang kuat, salah satunya al-Qur'an dan Hadist. Sebenarnya persoalan dakwah sudah ada sejak zaman dahulu sekaligus dengan penyelesaiaanya tetapi perlu dilihat lagi secara kontektual, sesuai dengan tantangan zaman sekarang ini.

\section{DAFTAR KEPUSTAKAAN}

Abdul karim zaidan (alih bahasa M.asywadi syukur) dasar-dasar ilmu dakwah, jakarta : madiun dakwah

Abdul munir mulkan, idiologi gerakan dakwah, episode kehidupan $M$. Natsir dan azhar basyir, yogyakarta : press, 1996.

Abdul munir mulkan, dakwah perspektif al-qur'an, Jakarta :TMF, 2002

Arifin, psikologi dakwah, suatu pengantar, Jakarta, bumi aksara, 1994

Asep Muhiddin, dakwah dalam perspektif al-qur'an, Bandung : Pustaka Setia, 2002

Mahmud yunus, Kamus arab Indonesia, Yayasan penyelenggara penterjemah/penafsir qur'an, jakarta : PT Hidakarya Agung : 1989 
Luis Ma'luf, almunjid fi al-lughat, Dar al masyriq, Beirut, 1997

Muhammad Fu'ad 'abdu al-baqi, Al mu'jam, Almufahras li alfazsh alqur'an Dar al-ma'rifah, Beirut, 1992

Departemen agama RI, al-qur'an dan terjemahannya, semarang : CV Toha Putra : 1990 